\title{
A complexidade do modelo fantástico intertextual de Cada corazón, un umbral
}

\author{
Rocío G-Pedreira \\ [Recibido, 31 marzo 2019; aceptado, 10 xuño 2019] \\ http://dx.doi.org/10.15304/bgl.54.5942
}

RESUMO A influencia recíproca dos sistemas literarios infantil e xuvenil e da literatura para adultos é unha constante dende as primeiras obras 'gañadas' que iniciaron o proceso de constitución da Literatura Infantil e Xuvenil. O presente artigo dá conta da evolución desa relación a través da análise da construción fantástica da novela para público adulto Every Heart A Doorway [traducida ao español como Cada corazón, un umbral], escrita por Seanan McGuire e publicada orixinalmente no 2016, gañadora dos Premios Hugo, Locus e Nébula 2017, algúns dos galardóns máis importantes da literatura fantástica. O foco de atención situarase en como se crea unha narrativa fantástica complicada de tipificar que se constrúe a través da intertextualidade coa fórmula fantástica máis utilizada no sistema literario Infantil e Xuvenil, na cal a crianza protagonista viaxa dende o mundo primario (realista) ao mundo secundario (fantástico), do cal regresa tras dunha experiencia enriquecedora e complicada que lle fai ollar o mundo con outros ollos.

PALABRAS-CHAVE: intertextualidade; literatura fantástica; Literatura Infantil e Xuvenil; Seanan McGuire; Wayward Children.

ABSTRACT The reciprocal influence between children and young adults and adults' literary systems has been a constant feature since those first works what weren't written for children but ended up being intended to them, which initiated the process of constitution of Children and Young Adults Literature. This study features the evolution of this relationship through the analysis of the fantasy construction of the novel for adults Every Heart A Doorway [translated into Spanish as Cada corazón, un umbral], written by Seanan McGuire and published originally in 2016, winner of the Hugo, Locus and Nebula awards 2017, some of the fantasy literature's most important awards. The focus will be in how a complex of typifying fantasy narrative is created through the intertextuality with the most common fantasy formula in the children and young adults literary system, in which the main character travels from the primary world (the realistic one) to the secondary world (the fantastic one), from where the child returns after a complex and rewarding experience which makes him see the world through different eyes. KEYWORDS: intertextuality; fantasy literature; Children and Young Adults Literature; Seanan McGuire; Wayward Children. 


\section{Introdución}

As dúas novelas protagonizadas pola pequena Alicia viaxando até o mundo das Marabillas asentan a creación do mundo fantástico nos soños e na capacidade imaxinativa da nena que, paralelamente, fan referencia ao talento do seu autor, Lewis Carroll. Teresa Colomer (2010: 123) destaca a relevancia crucial desta obra dentro do sistema infantil e xuvenil por supoñer "el origen real de la entronización del modelo literario fantástico para niños y la constitución decisiva de una literatura infantil y juvenil con voz propia". En efecto, os investigadores Michael Levy e Farah Mendlesohn, no monográfico dedicado á literatura infantil fantástica titulado Children's Fantasy Literature. An Introduction (2016), explican que a fantasía literaria como modalidade dentro da Literatura Infantil e Xuvenil (a partir de agora LIX) destácase por ter una dimensión propia e autónoma en relación á literatura de adultos, que se fixo máis clara a finais do século $\mathrm{XX}$ debido ao inesperado éxito de sagas como Harry Potter de J. K. Rowling, ou His Dark Materials de Philip Pullman. Porén, non estamos a falar de modalidades que se diferencian, especificamente, pola construción da trama, as técnicas de inclusión do fantástico ou a forma e presenza do elemento imposíbel, podendo tratarse de construcións análogas. A diferenza coa LIX fantástica reside na intencionalidade do autor de crear uns personaxes con intereses e motivacións próximas ao lectorado implícito e situacións que lles resulten atractivas e suxestivas, permitindo a conexión efectiva (e afectiva) entre ambos suxeitos. Gates, Steffel e Molson (2003: 9) afirman que se trata dun requisito fundamental nas obras fantásticas para este público,

because the fantasy is first of all a children's book, it must already have a child protagonist, and adult character, or a human-like protagonist -a talking animal, a toy come alive, some imaginary creature- with which a child can readily identify.

Unha das fórmulas máis repetidas na construción de narrativas fantásticas na LIX é a que asenta no desprazamento da crianza protagonista dende o mundo primario (real) até o secundario (fantástico), que tende a realizarse a través de portais. Así o fixeron tamén os irmáns Pevensey cara a Narnia na heptaloxía escrita por C. S. Lewis ou Wendy e os seus irmáns voando ao País de Nunca Xamais na obra de James M. Barrie. Son moitos outros os títulos que se poderían mencionar, pero a escolla destes concretos non é froito do azar. En todas estas novelas a viaxe ao mundo secundario repítese en máis 
dunha ocasión, até transformar o mundo fantástico nun mundo posíbel, que lexitima a súa existencia nunha dimensión paralela. Pero o seu acceso ten unha limitación moi concreta: só apto para non adultos.

Neste momento do desenvolvemento do estudo, a hipótese de partida sería: como afectaría esa imposibilidade dos protagonistas de volver aos mundos secundarios se foran persoas reais e non personaxes de ficción? Máis aínda se se ten en conta que é precisamente neses mundos onde atopan o seu lugar e desenvolven o sentimento de pertenza. Arredor desta premisa constrúe a súa ficción fantástica a escritora estadounidense Seanan McGuire (California, 1978), autora de Every Heart A Doorway ${ }^{1}$, primeira parte da serie de novelas coñecida como Wayward Children, gañadora dos Premios Hugo, Locus e Nébula 2017. A novela foi publicada orixinalmente no 2016, a segunda da serie un ano máis tarde, a terceira no 2018 e a cuarta a comezos deste ano. Trátanse todas elas de historias independentes centradas en momentos da vida de varios personaxes que son introducidos na primeira entrega e relacionados, todos eles, coa "Residencia para niños descarriados de Eleanor West".

A obra sobre a que xira este artigo está protagonizada por Nancy, unha moza de dezasete anos que desaparecera varios meses do seu fogar, cuxo carácter e forma de ser cambia radicalmente cando regresa, tratándose agora dunha rapaza apagada, reservada e moi estática, cuxo gusto estético e estilo de vestir está protagonizado pola cor negra e as prendas pouco chamativas. Cando volve ao seu fogar, Nancy explícalle aos pais que cruzou un portal que a levou ao Inframundo, aos Salóns dos Mortos, onde habitou durante anos co Señor dos Mortos, onde de verdade se sentira ela mesma por primeira vez na súa vida. Os pais de Nancy asumen que esta historia vén derivada do trauma causado polo secuestro e o que alí puido ver ou sufrir. Ante o fracaso ao intentar volver recuperar á nena que unha vez fora, deciden enviala á escola de Eleanor West e, na primeira reunión coa directora, explícaselles que alí intentan axudar a curar a adolescentes na mesma situación que a súa filla. $\mathrm{O}$ certo é que se trata dun discurso perfectamente pensado e teatralizado que Eleanor utiliza para convencer aos pais de que deixen con ela aos seus fillos, sen saber que a propia directora foi unha deses nenas que viaxou a un mundo

1 Para a realización deste traballo utilizouse a tradución ao castelán da obra feita por María Pilar San Román baixo o título Cada corazón, un umbral e publicada por Alianza Editorial no 2018, dentro da colección "Runas". 
fantástico e espera a posibilidade de volver mentres intenta axudar a outros coma ela e aprender máis sobre os portais e os mundos que están detrás.

Durante a estancia no centro comezan unha serie de asasinatos similares, nos cales os alumnos que aparecen mortos teñen extraída a parte do seu corpo que os caracteriza e fai especiais, que parece ser a motivación da aparición dos portais que lles dan entrada aos distintos mundos. A trama vai explorando a natureza de distintos personaxes, a súa vida antes e despois dos portais e o día a día na escola, que cambia radicalmente debido aos crimes que rematan por ser resoltos a nivel interno, posto que facelos públicos sería o fin da institución. Comézase por unha fantasía subliminal na cal a existencia do fantástico podería explicarse debido á capacidade de fabulación ou a unha resposta e concepción fantasiosa da realidade dos personaxes derivada dun evento traumático, que remata por cambiar as regras naturais da realidade para dar cabida á existencia efectiva do fantástico e de todos os mundos aos que se fai referencia.

O obxectivo da presente nota é analizar de que xeito se constrúe a trama da obra a través do diálogo intertextual cunha das máis recorrentes tipoloxías da LIX fantástica, facendo referencia tanto á deconstrución do modelo como punto de partida da trama como á referencia explícita no libro a obras reais e coñecidas da literatura fantástica que, a través dun xogo metaliterario, buscan darlle veracidade ao elemento fantástico. Por último, e aínda que dun xeito moito menos profundo, tamén se fai referencia á exploración de realidades e problemáticas contemporáneas, cuxa crítica social é posíbel grazas á presenza de mundos fantásticos, desbotando de xeito notorio os argumentos que seguen vendo esta modalidade como literatura "escapista".

\section{Cada corazón, un umbral: unha fantasía difícil de catalogar}

A novela escrita por McGuire comeza no mundo primario-realista, que nunca se abandona en ningún momento da historia. A información e as referencias aos mundos fantásticos fanas os propios personaxes cando recordan e falan das súas viaxes e de como eran eses lugares. No inicio, acompañamos a Nancy na súa chegada á escola, despois de que seus pais se reuniran coa directora e aceptaran internala, desesperados por non ser capaces de recuperar a filla que tiñan antes de desaparecer. Dende ese primeiro momento, 
o lectorado atópase perdido ante dúas posturas opostas entre as que se debe debater: aceptar que os mundos realmente existen e tomar partido polos residentes da escola, ou decantarse pola opción dos familiares, que cren que toda a fabulación das viaxes a mundos é consecuencia dalgún evento traumático vivido durante o período que estiveron desaparecidos.

Esta liña argumental continúa até ben avanzada a obra, mantendo a ficción dentro do campo das liminal fantasies ${ }^{2}$. Non obstante, esta percepción é só do lector, que pouco a pouco parece chamado a aproximarse á posición de Eleanor e dos demais alumnos debido a que a historia se focaliza neles, e os familiares pasan completamente a un segundo plano. Cando Nancy se converte en residente da escola empeza a entender que o seu caso non é único e que hai moitos máis coma ela, aínda que tamén diferentes, dependendo das personalidades de cada un e dos mundos a onde viaxaran. A dinámica de mundos, que será tratada no seguinte apartado do artigo, vaise explicando pouco a pouco a través da voz dos alumnos, de Eleanor e de Lundy, a terapeuta especializada en psicoloxía infantil, cuxo aspecto era dunha nena de oito anos. Ela tamén viaxara a un mundo cando era pequena, de onde sería expulsada ao cumprir dezaoito anos. Lundy pedíralle axuda ao boticario para impedilo e rematara por deixar o mundo despois de ir contra as normas e condenada a rexuvenecer unha semana cada mes de vida. Por esta razón, a muller adulta estaba atrapada nun corpo infantil que continuaba a minguar.

A primeira alumna que coñece Nancy é Sumi, tamén a primeira en ser atopada morta coas mans seccionadas. Era unha rapaza faltona e inquieta que desbotara a idea de aferrarse á esperanza e pensar en que había algunha po-

2 Ao longo do traballo tomarase como referencia teórica a taxonomía do fantástico proposta por Farah Mendlesohn $(2008,2016)$, que funciona como un intento de reconciliación da corrente todoroviana (Todorov, 1970 [1994]; González Salvador, 1984; Jackson, 1986; Camacho, 2003; Roas, 2001; Casas, 2008) e as alternativas teóricas que recoñecen a existencia do sistema literario infantil e xuvenil e as súas particularidades no relativo á modalidade do fantástico (Nikolajeva, 1988; Held, 1985; Gates, Steffel e Motson, 2003). As categorías establecidas por Mendlesohn son: portal-quest fantasy, que engloba as nocións de portal fantasy, un mundo fantástico ao que se accede a través dun portal, e quest fantasy, cando o protagonista parte dunha vida ordinaria e entra en contacto directo co fantástico a partir dunha viaxe exploratoria; inmersive fantasy, cando o fantástico non recibe ningún tipo de explicación xa que está normalizado dentro da realidade da ficción; intrusion fantasy cando o fantástico irrompe na dinámica do mundo realista, entendido como ordinario e predicíbel; e liminal fantasy, cando nun mundo que se identifica como real o fantástico dá sinais de existencia pero non se materializa claramente, causando no lector unha continua sensación de estrañeza; finalmente a autora fala do grupo de irregulares, onde coloca obras das que non contaba con suficientes puntos en común como para crear unha nova categoría. 
sibilidade de volver ao seu mundo, pero nunca deixara de crer nel, polo que fora rexeitada polos pais que remataran por falecer. Sumi é quen lle presenta a Kade, un rapaz transxénero que fora secuestrado polas fadas pensando que era unha nena e levado a través dun portal até que se deron conta de que aínda que non o parecera fisicamente, era un neno. Despois cobran importancia as personaxes das xemelgas Jack e Jill. A meirande parte dos alumnos sospei$\tan$ que Jack era a asasina porque cando viaxara ao seu mundo fora a aprendiz dun científico que reconstruía corpos con partes, levaba a cabo resurreccións e investigaba sobre a anatomía dos corpos. Pola outra banda, Jill convertérase na protexida do Amo das terras, un vampiro que esperaba o momento axeitado para transformala. Jack explica que foran expulsadas do mundo por un "problemilla con las fuerzas del orden locales" (McGuire, 2018: 51). O último mozo que completa o grupo do que se rodea Nancy é Christopher, quen viaxara ao País dos Ósos e se mantivera un pouco á sombra porque falar do seu mundo abertamente, como o facía Jack, supoñía ser rexeitado. A excepción de Kade, os mundos aos que eles viaxaran eran sombríos, escuros e habitados por mortos, demos ou tolos.

O feito de que Sumi non tivera familiares vivos facía máis fácil ocultar o asasinato para que os demais puideran seguir asistindo á escola normalmente, pero cando aparece morta Loriel cos ollos arrancados, Eleanor debe tomar unha decisión. Despois de advertirlles do perigo, ábrelles a porta da escola aos que queiran ir coas súas familias e poñerse a salvo, aínda que esa non é unha solución válida para a maioría deles, que non son comprendidos nin apoiados nos seus fogares. Tamén ofrece o seu portal aos que viaxaran a mundos similares ao seu para que se mantiveran a salvo, aínda que iso supoñía poñer en perigo a posibilidade de regresar. Por último, pídelle axuda a Jack para que borre todo rastro do corpo de Loriel. A rapaza, asistida por Kade, Nancy e Christopher, disponse a disolver o cadáver en ácido. Durante este labor, Jack analiza o corpo e confirma que a causa da morte son as implicacións da extirpación das partes extraídas, que fora realizada coa alumna aínda viva. Isto é o que lles permite empezar a construír a teoría de que os asasinatos buscaban coleccionar as partes que fan aos alumnos proclives a ter acceso a un portal.

Christopher protagoniza o momento no que o evento que rompe as leis da natureza se presenta de maneira explícita e a historia deixa de seguir a retórica das liminal fantasies para pasar a confirmar a existencia dos portais e, por tanto, desvelarse como unha portal-quest fantasy. Cando xa só quedan os ósos 
do corpo de Loriel, Christopher toca a súa frauta e o cadáver comeza a danzar seguindo as indicacións do mozo. Antes de levalo a un lugar do exterior onde darlle sepultura, Jack aproveita para preguntarlle quen fora o asasino, mais o esqueleto responde sinalando ao baleiro ao lado da rapaza. Esta pista, unido ao asasinato da profesora Lundy, que aparece co cerebro extirpado, e da desaparición de Seraphina, unha alumna de beleza inigualábel, parecen ir confirmando a teoría na mente de Jack de que alguén intenta crear un corpo a partir das partes dos demais para forzar a apertura dun portal. A última agresión é á propia Jack, que remata malferida pero viva, e confirma a súa sospeita: a culpábel era Jill. Jack aproveita este momento para descubrir a verdade, que ela decidira abandonar o mundo ao que viaxaran para salvar a vida de súa irmá, que era perseguida polos aldeáns logo de matar a varios mozos do pobo para intentar conseguir o beneplácito do Amo e que a transformara en vampiro. Para evitar que rematara por asasinar tamén a Seraphina, Jack apuñala a súa irmá, para inmediatamente despois abrir o portal e cruzalo co corpo de Jill, onde a podería resucitar e, deste xeito, evitar que se convertera nun mostro. Só os vivos poden transformarse en vampiros.

O capítulo final da obra volve sorprender ao lector e dar un xiro inesperado. Despois de que as cousas se tranquilizan e Nancy parece atopar un lugar no mundo real que non lle é totalmente remiso, onde se proxecta de cara ao futuro concibindo a posibilidade de aprender a ser nalgunha medida feliz, o achado dunha carta deixada por Sumi antes de morrer co obxectivo de chegar á rapaza se rematara por renderse e volver con seus pais, provoca a aparición do portal. A carta en cuestión lanzaba unha mensaxe de empoderamento e autodeterminación que lle recordaba a Nancy que a única que pode decidir sobre o seu futuro é ela mesma:

No eres el arcoíris de nadie.
No eres la princesa de nadie.
No eres la puerta de nadie, salvo la tuya, y la única persona
que puede decirte cómo termina tu bistoria eres tú (McGuire, 2018: 180).

En síntese, a obra de McGuire remataría por agruparse dentro do último grupo do que fala Mendlesohn, as fantasías irregulares, cuxas particularidades non fan posíbel a súa inclusión dentro de ningún dos demais tipos. A súa principal característica é a volubilidade dos aspectos que a converterían nunha tipoloxía fixa e a viaxe que fai por todas elas. Sería o que Mendlesohn denomina "metatextual fantasies", onde os personaxes existen nun mundo 
imaxinario dentro do mundo real, pero levado ao extremo: Eleanor, Nancy e os demais residentes na escola pertencen ao mundo real, pero o sentimento de pertenza, entendido como a sensación de benestar creada por un contexto que complementa ao individuo e o fai sentir propio desa realidade e libre nas súas accións e pensamentos, só o conseguen nos mundos imaxinarios.

Entón, podería pensarse que máis que personaxes propios do mundo realista, se trata de personaxes do mundo fantástico que non atopan o seu lugar no primario porque, en realidade, non pertencen a el? Aínda que sería unha hipótese interesante, a autora utiliza esta incomodidade dos personaxes coas convencións sociais do mundo primario para facer unha alegación a favor da liberdade de escoller quen somos e que queremos ser, e a falta de apoio dunha sociedade estereotipada e "estereotipadora", que parece só feita para os que se atopan dentro das marxes do "normal" ou do "politicamente correcto". Por exemplo, Kade é un mozo transxénero que nunca foi aceptado por seus pais, de maneira que se sentía encerrado nun corpo feminino que non lle era propio, e acaba por ser secuestrado polas fadas crendo que era unha nena. Non obstante, os seres do mundo fantástico viron máis alá do sexo biolóxico e remataron por expulsar a Kade porque parecía unha nena, vestía como tal, pero non o era en realidade. A pesar de que isto supuxo a expulsión do mozo do mundo fantástico, foi un antes e un despois na súa liberación como persoa e da aceptación que fai de si mesmo.

Por outra parte, tamén nos atopamos coas xemelgas Jack e Jill ${ }^{3}$. No seu caso, ambas foron traídas ao mundo por seus pais na busca da aceptación social dos seus respectivos grupos de iguais. A nai quería unha nena bonita, educada e correcta da que presumir, e o pai un neno forte, decidido e emprendedor que remataría por seguir os seus pasos cun traballo lonxe do ambiente doméstico. Ningún dos dous vían o feito de ter descendencia como algo máis alá dun medio para conseguir un fin puramente egoísta e narcisista, e cando descobren que esperan dous bebés e non un comezan a soñar coa consecución das aspiracións de ambos dunha sentada. Por iso, cando nacen dúas nenas iguais, proxectan sobre elas a realidade que queren ver e non a verdadeira, e constrúen dúas personalidades opostas que non coinciden coa

3 A novela posterior a Cada corazón, un umbral profunda na historia das xemelgas e as súas vivencias no mundo portal ao que viaxan, titulada Ahí abajo, entre raíces y huesos, e publicada en español por Alianza Editorial no 2018. 
esencia e a natureza das pequenas. Cando finalmente ambas viaxan a través do portal, séntense libres de deixar saír as súas personalidades e rematan por descubrir que seus pais as encerraran con expectativas e imposicións contrarias a elas mesmas. Unha crítica directa á sociedade patriarcal e ao machismo que desencadea a creación de arquetipos de xénero que coartan as liberdades das persoas, mulleres e homes.

Mais as mensaxes feministas que condenan as situacións sociais opresoras que non permiten ás nenas elixir e actuar con liberdade son tamén tratadas noutros momentos da obra. Nalgunha das ocasións son reflexións que xorden a partir da visión ou interpretación que fan da realidade os personaxes, como neste fragmento onde Nancy compara a dieta rica en ferro que segue Jill para ser máis apetecíbel para o seu Amo vampiro coa das rapazas da súa idade que coñecera:

Toda su vida había conocido chicas que estaban a dieta. Aunque en muy pocas ocasiones, si acaso en alguno, con el objetivo de tener la sangre rica en hierro. La mayoría andaba tras una cintura más fina, un cutis más radiante o un novio más rico, estimuladas por un aborrecimiento hacia sí mismas profundamente arraigado, fabricado para ellas antes de que tuviesen edad suficiente para darse cuenta de en qué tipo de arenas movedizas se estaban hundiendo (McGuire, 2018: 51).

Ademais, McGuire decide que as nenas sexan as máis proclives a desaparecer e cruzar a través dun portal e xustifica esta elección no papel secundario que tradicionalmente viñeron interpretando, derivado da exclusión das mulleres do ámbito público, forzándoas a desempeñar roles secundarios e menos visíbeis. Na novela, a terapeuta Lundy responde á pregunta de Nancy sobre por que son máis rapazas na escola facendo referencia ao machismo como unha actitude aprendida e non innata no ser humano:

- Porque eso que se dice de que "los niños son más revoltosos que las niñas" es una de esas profecías que acarrean su cumplimiento -respondió Lundy-. En general, los niños son demasiado bulliciosos para que se los pase por alto o se pierdan con facilidad; cuando desaparecen de casa, los padres organizan batidas de rescate para que los busquen en los pantanos y los alejen de los estanques. No es algo innato, sino aprendido, pero que los protege de las puertas, los mantiene en la seguridad del hogar. Llámelo ironía si quiere, pero pasamos tanto tiempo esperando que nuestros niños se desvíen del buen camino que nunca tienen oportunidad de hacerlo. En el silencio de los hombres se repara. Con el silencio de las mujeres se cuenta (McGuire, 2018: 61-62). 


\section{O dobre xogo intertextual}

A partir dos estudos de Mikhaïl Bakhtine, Julia Kristeva acuñou no 1969 o termo intertextualidade para facer referencia á necesaria relación dun texto novo cos demais xa existentes, afastándose da concepción dominante nos estudos literarios e culturais das correntes formal-estruturalista, filolóxica e historiográfica. Segundo a autora, "any text is constructed as a mosaic of quotations; any text is the absorption and transformation of another. The notion of intertextuality replaces that of intersubjectivity, and poetic language is read as at least double" (Kristeva, 1986: 37). Isto supón que todo autor, durante a creación da súa obra, mantén un diálogo explícito e/ou implícito cos textos anteriores. Aínda que houbo outros importantes autores que continuaron a falar do tema ${ }^{4}$, a madurez filosófica do termo chega nos anos oitenta de man de Gérard Genette. Na súa obra Palimpsestes. La Littérature au second degré (1982), o autor agrupa dunha maneira global a interrelación de diversos textos baixo o termo "transtextualidade", e define cinco tipos de relacións transtextuais: a intertextualidade, cando existe presenza textual efectiva dun texto noutro, ben como alusión, plaxio ou cita; a paratextualidade, que sería a relación dun texto cos paratextos que o rodean; a metatextualidade, a relación

22 crítica que establece un texto con outro do que fala sen ter por que citalo ou nomealo; hipertextualidade, que sería a inclusión dun texto A -hipotextonun texto posterior B -hipertexto-, como acontece no caso da parodia, da reescritura ou da tradución; e, por último, arquitextualidade, unha relación completamente muda que, ao máximo, articula unha mención paratextual de simple pertenza taxonómica.

$\mathrm{Na}$ entrada correspondente ao termo intertextualidade do Dicionario de termos literarios dirixido polo Equipo Glifo (sen data), explícase que existe un concepto máis operativo de intertextualidade que busca identificar, clasificar e interpretar a vinculación máis ou menos directa dun texto con outros aos que alude de xeito explícito ou implícito. Deste xeito, fálase de dous puntos de vista diferentes:

o primeiro punto de vista é transcendental (intertextualidade como condición de posibilidade de textos) e considera a obra literaria desde unha perspectiva esencialmente teórica, o segundo é empírico (intertextualidade como vinculación empírica entre uns textos e outros) e se relaciona coa crítica literaria, no sentido de que supón a análise concreta dunha obra determinada.

4 Véxase Roland Barthes (1973), Michael Riffaterre (1979) ou Cesare Segre (1982). 
A análise proposta neste artigo atópase na segunda liña mencionada. McGuire pon en práctica diversos mecanismos intertextuais para elaborar unha reconstrución da fórmula narrativa do fantástico máis utilizada na LIX que corresponde ao grupo das portal-quest fantasies, é dicir, aqueles relatos nos que a crianza protagonista viaxa a través dun portal dende o mundo primario-realista ao mundo secundario-fantástico. Nesta ocasión non se trata dun hipotexto concreto posto que non se fai referencia a unha única obra, senón á forma de construír unha tipoloxía de narrativa fantástica. Este xogo intertextual constrúese en base a dous núcleos: a intertextualidade co modelo das portal-quest fantasy que permite lexitimar a realidade dos portais e dos mundos fantásticos dentro da realidade da ficción, e a construción dun complicado sistema de mundos cunha complexa estrutura teórica estudada e traballada dentro da escola.

No primeiro caso, podemos atoparnos referencias explícitas a obras concretas do modelo, que axudan a lexitimar a veracidade do fantástico atribuíndolles unha existencia no campo do real dentro da ficción, ou reforzando a súa natureza literaria. En primeiro lugar, cando Nancy comeza a coñecer máis datos "reais" sobre a viaxe a través de portais da man dos seus compañeiros e profesoras fai referencia a Alice in Wonderland (1865) de Lewis Carroll, sen deixar claro se a realidade da ficción lle dá veracidade á historia de Alicia alén do literario:

- Bueno, de pequeña leí Alicia en el País de las Maravillas, pero jamás pensé demasiado en cómo habría sido para Alicia regresar a su mundo de partida. Me imaginé que se habría limitado a encogerse de hombros y seguir adelante. Pero yo no puedo hacer eso. Cada vez que cierro los ojos, me encuentro de vuelta en mi verdadera cama, en mi verdadera habitación, y el sueño es todo esto (McGuire, 2018: 52-53).

Outra das referencias explícitas que se realiza é a heptaloxía sobre The Chronicles of Narnia (1950-1956) de C. S. Lewis. Nunha conversación que manteñen os alumnos con Eleanor e Lundy, dous deles enfrontan as súas perspectivas con respecto á veracidade das viaxes dos irmáns Pevensey, posto que un deles as utiliza como referencia para aferrarse á esperanza de que o portal que o leva ao seu mundo remate por aparecer, e o outro retorna as obras á súa existencia puramente literaria, a "real" dentro e fóra da novela:

- ¿Y qué pasa con mundos como Narnia? -preguntó Christopher-. Esos niños atravesaron todo tipo de puertas distintas, y siempre acababan volviendo con el gran león parlante. 
- Eso es porque Narnia era una alegoría cristiana que se hacía pasar por una serie de fantasía, gilipollas -le espetó uno de los otros chicos-. C. S. Lewis nunca atravesó puerta alguna. No sabía cómo funcionaban. Quería contar una historia y, como probablemente había oído hablar de niños como nosotros, se inventó todas esas paridas. Lo mismo que todos esos otros autores. Se inventaron paridas y se hicieron famosos. Nosotros contamos la verdad y nuestros padres nos meten en esta loquería con pretensiones (McGuire, 2018: 106).

De maneira menos explícita, o Peter and Wendy (1911) de James M. Barrie aparece de maneira reiterada na imposibilidade dos adultos de volver aos mundos fantásticos nas vivencias de Eleanor e Lundy. No primeiro caso, a historia da directora é distinta á meirande parte do alumnado, posto que ela sabe onde está o seu portal, pero non cumpre o requisito máis importante para volver, ser unha nena:

No hacía falta que dijese qué era lo que más deseaba, porque ellos compartían su anhelo, su deseo implacable y brutal: lo que más deseaba era una puerta, y lo que esperaba al otro lado. Sin embargo, a diferencia del resto, Eleanor sabía dónde estaba su puerta, pero por el momento estaba cerrada para ella, hasta que consiguiera encontrar el camino de vuelta a la infancia (McGuire, 2018: 106).

Esta é a mesma condición coa que se atoparon Wendy e seus irmáns, quen desbotaron a idea de volver por darlle prioridade ao valor de ter unha nai. Eleanor cre que ten unha oportunidade e así llo explica a Kade, quen despois llo relata a Nancy:

- Me dijo que estaba esperando a padecer demencia senil, igual que les había pasado a sus padres, porque cuando pierda la cabeza lo suficiente, volverá a ser capaz de tolerar el Sinsentido. Va a estar al frente de esta escuela hasta que olvide por qué no regresa a su mundo y, entonces, cuando sí regrese, podrá quedarse (McGuire, 2018: 74).

No caso de Lundy, ela ten aspecto de nena despois de intentar evitar medrar para poder quedarse no seu mundo. Igual que sucedeu no caso dos demais alumnos, o mundo fantástico é o que ve realmente a persoa que é cada un deles tras o seu físico, e a terapeuta perde toda oportunidade de volver porque, na realidade, ela xa é adulta.

Por último, tamén se fai referencia a personaxes propias da literatura oral e do folclore, como vampiros, mortos viventes, trasgos ou fadas, que van aparecendo nos relatos sobre os distintos tipos de mundos aos que viaxan os alumnos. 
Logo de lexitimar a veracidade da existencia de mundos fantásticos accesíbeis a través de portais que para o lector só existen a nivel literario, a novela desenvolve unha complicada estrutura teórica para o entendemento do fenómeno que é transmitida por Eleanor e Lundy ao alumnado. Na novela utilízase o "mundo real" e os catro puntos cardinais, norte, sur, este e oeste, para crear unha rosa dos ventos aplicábel aos mundos portal cuxas direccións principais son Sensentido, Lóxica, Maldade e Virtude. Ademais, tamén existen subdireccións secundarias que poden ou non coincidir con un lugar. Jack explícalle a Nancy a relación das direccións principais neste fragmento bastante clarificador:

La mayoría de mundos o bien son altos en Sinsentido o bien lo son en Lógica, y sobre esa base se añade un cierto grado de Maldad o Virtud. Un sorprendente número de mundos Sinsentido son Virtuosos. Es como si fuesen capaces de mantener la atención el tiempo suficiente para maldades que vayan más allá de travesurillas sin importancia (McGuire, 2018: 52).

De maneira gráfica, os mundos portais responderían á seguinte figura:

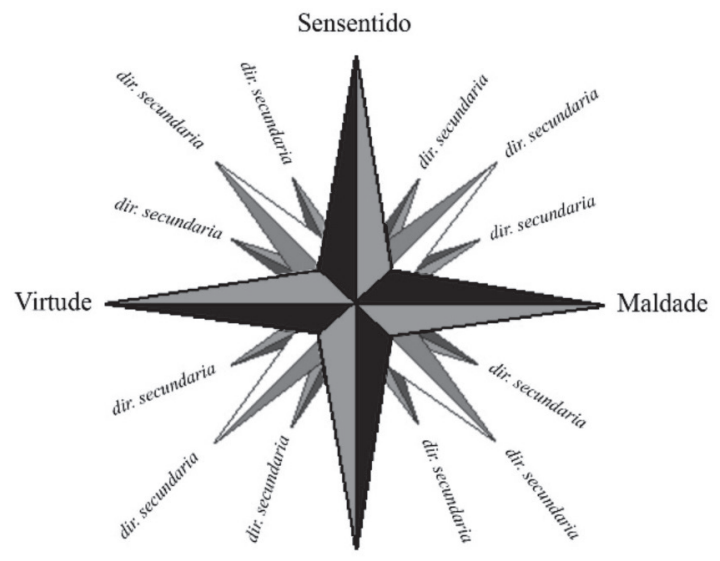

Figura 1. Rosa dos ventos dos mundos portal.

A complexa multitude de conexións que establece a novela de McGuire con obras fantásticas anteriores demándalle ao lector unha bagaxe literaria ${ }^{5}$ previa na cal predominen as obras literarias infantoxuvenís. Non obstante, Cada corazón, un umbral non está pensada para o público máis novo, non

5 Dita bagaxe corresponde ao termo de intertexto lector acuñado por Antonio Mendoza Fillola (2004: 144) que o define como "el mecanismo que activa selectivamente saberes y estrategias para establecer asociaciones de carácter metaliterario e intertextual". 
é a infancia o seu lectorado implícito nin está dentro dunha colección desas características. A obra busca lectores que boten a vista atrás e recorden como recibían e procesaban esas narrativas en estadios evolutivos anteriores e preséntase como un reto ao alcance dos que non esquecen nin cuestionan a capacidade do fantástico de remover e de transcender.

\section{Conclusión}

A realización do presente artigo permitiu certificar varias hipóteses inicias arredor da relación contemporánea entre os sistemas literarios infantil e xuvenil e o da literatura de adultos a través da análise dunha obra fantástica tan diferente, creativa e suxestiva como a de McGuire.

En primeiro lugar, esta obra dá conta da existencia de relacións intertextuais de obras de adultos que beben directamente da LIX, aínda que sexa máis recorrente ao contrario, e que o fan explícito na construción do hipertexto. Ademais, tamén deixa patente que a diferenza entre a fantasía para os máis novos e a dirixida a adultos non reside na trama que se conte. Unha historia sobre uns nenos que buscan a maneira de volver cruzar os portais que os levan a mundos fantásticos que algunha vez tiveron visitado parece máis proclive a formar parte dunha colección dirixida aos máis novos. McGuire demostra que o que importa é o "como se conta", por enriba do "que se conta”, e constrúe unha obra afastada dos intereses máis próximos á infancia posto que a intención da autora non é chegar a ese lectorado. O hipertexto final, dentro do sistema literario, mira de fronte ao sistema infantoxuvenil sen sentirse superior e establece un diálogo entre iguais.

Por outra parte, a existencia desta novela tamén segue a contrariar a afirmación de que a fantasía non pode comprometerse coa sociedade e as súas problemáticas e desenvolver historias con mensaxes e críticas que non deixen indiferente a ninguén. A suposta banalidade da fantasía non se pode sustentar nunha aproximación superficial a estas obras, que precisan de dous niveis de lectura: o propio da decodificación da mensaxe e o correspondente á decodificación da intencionalidade do elemento fantástico, sen que a xustificación da súa existencia sexa un aspecto ou criterio avaliábel no xuízo estético dunha obra. 
A escolla de Cada corazón, un umbral para a realización do estudo vén motivada pola calidade da novela, que supuxo o seu recoñecemento tamén a nivel de premios, polo eloxio que fai da infancia sen ser o seu lectorado implícito e buscando a complicidade dos adultos, pola escolla dun modelo fantástico que segue falto de estudos e visibilidade, especialmente en España e, ademais, porque é unha obra escrita por unha muller. Isto pode parecer algo sen importancia, e co tempo así debe ser; pero, a día de hoxe, segue sendo necesario reivindicar a figura das mulleres que escriben obras de modalidades xenéricas como a fantasía, que durante moito tempo foi etiquetada como "territorio de homes".

Rocio G-Pedreira

CIEC-IE-Universidade do Minho/ ICE-Universidade de Santiago de Compostela

\section{Bibliografía}

Barthes, Roland. 1973. Le plaisir du texte. París: Editions Du Seuil.

Camacho Guizado, Eduardo. 2003. "Acerca de los géneros de lo fantástico, lo maravilloso y la mitoficción”, en Literatura: teoría, historia, crítica, ${ }^{\circ}{ }^{5}$, pp. 61-78. DOI http://dx.doi.org/10.15446/lthc.

Colomer, Teresa. 2010. Introducción a la literatura infantil y juvenil actual. Madrid: Síntesis.

Equipo Glifo. 1998. Dicionario de termos literarios. Santiago de Compostela: Xunta de Galicia/Centro Ramón Piñeiro para a Investigación en Humanidades. http://www.cirp.gal/pls/bal2/f?p=106:2:4533450474228408427::NO:2:P2_ TERMO:intertextualidade [Consulta 25/02/2019].

Gates, Pamela S., Steffel Susan B. e Molson, Francis J. 2003. Fantasy Literature for Children and Young Adults. United States of America: Scarecrow Press.

Genette, Gérard. 1982. Palimpsestes. La Littérature au second degré. París: Editions Du Seuil.

González Salvador, Ana. 1984. "De lo fantástico y de la literatura fantástica", en Anuario de Estudios Filológicos, v. 7, pp. 208-226.

Held, Jacqueline. 1985. Los niños y la literatura fantástica, función y poder de lo imaginario. Barcelona: Paidos. 
Jackson, Rosemary. 1986. Fantasy: literatura y subversión. Buenos Aires: Catálogos Editora.

Kristeva, Julia. 1969. Semeiotiké. Recherches pour une sémanalyse, París: Editions Du Seuil.

Kristeva, Julia. 1986. "Word, dialog and novel", en The Kristeva Reader (ed. Toril Moi). New York: Columbia University Press, pp. 34-61.

Levy, Michael e Mendlesohn, Farah. 2016. Children's Fantasy Literature. An introduction. United Kingdom: Cambridge University Press.

McGuire, Seanan. 2018. Abi abajo, entre raíces y huesos. Madrid: Alianza Editorial, colección Runas.

McGuire, Seanan. 2018. Cada corazón, un umbral. Madrid: Alianza Editorial, colección Runas.

Mendlesohn, Farah. 2008. Rhetorics of fantasy. United States of America: Wesleyan University Press.

Nikolajeva, Maria. 1988. The Magic Code: the use of magical patterns in fantasy for children. Stockholm: Almqvist \& Wiksell International.

Nikolajeva, Maria. 2012. "The development of children's fantasy”, en The Cambridge Companion to Fantasy Literature (eds. Edward James e Farah Mendlesohn). United Kingdom: Cambridge University Press, pp. 50-61.

Riffaterre, Michael. 1979. La Production du texte. París: Editions Du Seuil.

Roas, David (comp.). 2001. Teorías de lo fantástico. Madrid: Arco/Libros S.L.

Segre, Cesare. 1982. "Intertestuale-Interdiscorsivo. Appunti per una fenomenologia delle fonti", en La parola ritrovata. Fonti e analisi letteraria (eds. Costanzo di Girolamo e Ivano Paccagnella) Palermo: Sellerio, pp. 15-28.

Todorov, Tzvetan. 1994. Introducción a la literatura fantástica. México: Ediciones Coyoacán. 